\title{
El estudio de los orígenes del islam en las últimas cuatro décadas: controversias y perspectivas
}

\section{The Study of Islamic Origins in the Last Four Decades: Controversies and Perspectives}

\author{
Carlos A. Segovia ${ }^{1}$ \\ UCJC/UNED (España)
}

Recibido: 30-11-18

Aprobado: 08-01-19

\section{Resumen}

Prácticamente ningún estudioso duda de que la llamada historia deuteronomista o "de la segunda Ley", incluida en el corpus bíblico para configurar algunos de los principales libros que lo componen, fue redactada durante el exilio babilónico y revisada posteriormente. Y no se produce esa duda porque el estudio histórico-crítico del texto bíblico, así como el análisis histórico del periodo correspondiente, han venido a mostrar, que la compilación y definitiva puesta por escrito de los libros históricos de la Biblia tuvo lugar en una época mucho más tardía de lo dogmáticamente establecido. Pues bien, similar método histórico-crítico se aplica hoy en día también al estudio del texto coránico, si bien con mucho menor seguimiento y aún rodeado de una serie de estereotipos narrativos asociados al dogma islámico pero que entre numerosos estudiosos no es menos dogmático.

Palabras-clave: Método histórico-crítico, Corán, Vulgata Uthmaní, John Wansbrough, Sincretismo.

\footnotetext{
${ }^{1}$ (carlos.segovia@slu.edu) Profesor Titular de Estudios Religiosos en la Saint Louis University, Campus de Madrid. Durante los últimos 10 años ha trabajado en el canto del Early Islam y en la actualidad se dedica al estudio comparado de la religión, la semiótica y la proyección de la subjetividad sobre un fondo de capitalismo mundial integral. Entre sus publicaciones en el campo del Early Islam destacan: The Quranic Noah (De Gruyter, 2015), The Quranic Jesus (De Gruyter, 2018), Remapping Emergent Islam (Amsterdam University Press, en prensa), Geobiosemiocapitalism and Cosmopolitics (en prensa).
} 


\begin{abstract}
Virtually no scholar doubts that the so-called Deuteronomist - 'Second Law'- history, included in the biblical corpus to configure some of the main books that compose it, was written during the Babylonian exile and subsequently revised. And this doubt does not take place because the historicalcritical study of the biblical text, as well as the historical analysis of the corresponding period, have come to show that the compilation and definitive writing of the historical books of the Bible took place in a much later time than the dogmatically established. A similar historical-critical method is also applied today to the study of the Qur'anic texts, although with much less follow-up and still surrounded by a series of narrative stereotypes associated with Islamic dogma but which among many scholars is no less dogmatic.
\end{abstract}

Key-words: Historical-critical method, Qur'an, Uthmani Vulgata, John Wansbrough, Sincretism.

The facts are of value if they are significant, and their significance lies in the way or ways in which they have been interpreted and preserved.

J. Wansbrough

A casi nadie se le ocurriría dudar hoy de que la historia deuteronomista, incluida en el corpus bíblico y que da forma a algunos de los principales libros que lo componen, fue redactada durante el exilio babilónico y revisada posteriormente (Rendtorff 1983). El estudio histórico-crítico del texto bíblico y el análisis histórico del periodo

correspondiente han venido a mostrar, en efecto, lo que ya el segundo libro de los Macabeos señala de manera muy precisa, a saber: que la compilación y definitiva puesta por escrito de los libros históricos de la Biblia tuvo lugar en época de Nehemías (2 Mac. 2.13). Paralelamente, el hallazgo de los manuscritos de Qumrán y su posterior publicación y estudio han puesto de relieve la existencia de importantes variantes textuales en la transmisión del corpus bíblico hasta bien entrada nuestra era (Trebolle Barrera 1997; Ulrich 1999), de lo que, más limitadamente, las diferencias existentes entre las traducciones griegas de la Biblia y el texto masorético daban ya alguna idea con anterioridad (Fernández Marcos 1998). En suma, hoy sabemos que fue en la época del segundo templo (Boccaccini 2002; Sacchi 2004) cuando el judaísmo pretalmúdico tomó cuerpo en términos doctrinales, litúrgicos y escriturarios.

Así como la experiencia del exilio había marcado intensamente la mentalidad judía a lo largo del siglo VI a.C. (Newsome 1979), y ello hasta el punto de que se consideró oportuno relatar la historia de los orígenes en tanto 
que historia de un éxodo prolongado, la nueva clase sacerdotal imprimió tras la restauración del templo un nuevo cariz a las narraciones previas modificándolas en aspectos bien relevantes; cf. e.g. 1 Reyes 2.1-4; 1 Crónicas 28.1-10, donde alternan y se oponen dos relatos (monárquico el uno, sacerdotal el otro) de un mismo hecho; o Zacarías 3.1-5; 12.2-

14, donde la magnitud del conflicto que enfrentó al sacerdocio sadoquita y a los partidarios de la casa de David al regreso del exilio trata de mitigarse. Casi nadie dudaría hoy tampoco de que el cristianismo, Pablo incluido (Sanders 1977; Dunn 2007) por sorprendente que ello pueda aún parecer a algunos, representó en sus inicios un fenómeno rigurosamente judío (Nickelsburg 2003, 2006) que si terminó por quedar del algún modo al margen de la historia religiosa de Israel fue debido a dos motivos: primero, el incremento de fieles procedentes de la gentilidad frente al cada vez más reducido número de fieles originariamente judeocristianos; y segundo, la anatemización de los grupos judíos apocalípticos por parte del judaísmo rabínico, cuya reforma políticoreligiosa (Dix 1953) se saldó con la final exclusión de los judeocristianos de la sinagoga (Mimouni 1998). Sea como fuere, Jesús fue judío, acudió al templo, participó en la liturgia sinagogal y entendió su misión, principalmente, a la luz de las nociones elaboradas por el judaísmo apocalíptico de corte esenio y henóquico (Murphy 1991; Nodet y Taylor 2002; Charlesworth 2005), de las que es igualmente deudora la primitiva fe cristiana (VanderKam y Adler 1996).

Por su parte, los evangelios y otros varios escritos, canónicos o no, compuestos por las primeras comunidades cristianas reflejan las diferentes interpretaciones de las que dicha fe fue objeto entre sus miembros (Brown 2002), sin que sea posible reducir sin más unas interpretaciones a otras ni siempre fácil conciliarlas: las controversias teológicas suscitadas en los primeros siglos de la historia de la iglesia dan buena muestra de ello, siendo así que la asignación de posterioridad temporal a las con el tiempo llamadas tendencias heterodoxas frente a las ortodoxas plantea más problemas de los que aparentemente resuelve (Boyarin 2004). De nuevo y al igual que con el judaísmo, el método históricocrítico aplicado al estudio de las fuentes textuales y el análisis histórico de los orígenes del cristianismo, sobre el que vienen aplicándose desde hace décadas las herramientas propias de la investigación histórica, nos permite hoy conocer mejor el proceso a través del cual se constituyó el cristianismo, primero como una corriente interna al judaísmo y luego en tanto quereligión independiente.

El islam representa, sin embargo, un caso aparte, y los estudios sobre sus orígenes una anomalía en el ámbito académico internacional. No sólo los fieles musulmanes, sino también los estudiosos en su mayoría se muestran aún hoy por lo general reacios (Donner 1998) ante la posibilidad de estudiar los orígenes del islam en términos histórico-críticos. Unos y otros se contentan las más de las veces, en efecto, con interpretar literalmente los primeros escritos 
conservados relativos a la historia temprana del islam, aun a sabiendas de que esos mismos escritos fueron redactados unos ciento cincuenta años después de los sucesos que pretenden describir. Es, sin ir más lejos, el caso de Ibn Ishâq (m. 767), del que lo único que se nos ha conservado es lo transmitido por Ibn Bukayr (m. 814-15) e Ibn Hishâm (m. 830), cuyas versiones no siempre concuerdan, e indirectamente vía Tabarî (m. 923) por Salama b. al-Fadl

(m. 807); y cuya obra fue redactada por encargo de las autoridades abasíes, más exactamente a petición del califa al-Mansûr (754-75), lo que la dota de un cariz eminentemente político. Por otra parte, y aunque en este ámbito los estudios han avanzado algo más, el texto coránico sigue siendo estudiado a menudo como un corpus más o menos cerrado, como si frente a la recensión oficial uthmaní no hubiera habido otras: las de Salîm b. Mâqîl, al-'Abbâs, 'Alî b. Abî Tâlib, Abû Mûsâ al-Ash'arî, 'Ubayy b. Ka'b e Ibn Mas ‘ûd, según nos informa Ibn Abî Dâwud (m. 929), a quien debemos asimismo la noticia de la supresión del códice de Hafsa bt. 'Umar por parte de Marwân b. al-Hakam y la relativa a las adiciones realizadas por 'Ubayd Allâh b. Ziyâd sobre el códice uthmaní; testimonio éste al que hay que sumar el de Suyûtî acerca de las adiciones efectuadas por el propio 'Umar b. al-Khattâb sobre la recensión de Zayd b. Thâbit, que habría a su vez servido de base textual a 'Uthmân. Los esfuerzos de algunos investigadores (Puin 1996) por demostrar la antigüedad de la vulgata uthmaní se han visto por lo demás frustrados (Amir Moezzi y Kohlberg 2005), por lo que la idea de una compilación tardía del texto coránico tal y como hoy lo conocemos ha terminado por imponerse (Deroche 2007).

En cuanto a la colección del hadîth, no es este lugar en que reproducir las muy razonables dudas vertidas sobre su autenticidad por Goldziher (1889-90) y Schacht (1953), pues podemos más simplemente deducir de uno de los primeros comentarios coránicos conservados como es el de Muqâtil b. Sulaymân (m. 765) la inexistencia de tradiciones proféticas consensuadas antes de último tercio del siglo VIII. Dicho con otras palabras, si bien es indudable que el islam, sea lo que sea lo que debamos entender por él hasta finales del siglo VII o mediados del VIII, a lo cual aludiré más adelante, surgió hacia mediados del siglo VII, las fuentes sobre las que suele de ordinario apoyarse el estudio de sus orígenes, y por ende la propia historiografía islámica, no son anteriores a la segunda mitad del siglo VIII o, quizá, a la primera mitad del siglo IX.

Bien mirado, el estudio crítico de los orígenes del islam no ha hecho tampoco sino confirmar lo que las propias fuentes islámicas nunca han ocultado, a saber: las dificultades inherentes al estudio del periodo formativo de la religión islámica a partir de los datos internos sobre los que la tradición musulmana ha construido su relato; un relato que suele pasar por alto los problemas acumulados por las fuentes a las que él remite (Prémare 2002). He aquí un ejemplo a la vez sencillo y elocuente: Ibn Zabâla (segunda mitad del 
siglo VIII), autor de una de las dos monografías que nos son conocidas sobre Medina, de la que únicamente se nos han conservado los extractos citados por Samhûdî (m. 1506), define Yathrib como 'la metrópoli de las ciudades de Medina (sic!)'. Samhûdî, por su parte, observa que la ortografía es incierta (¿Yathrib?, ¿Athârib?) y se pregunta: ‘¿Es éste el nombre de la región de la que forma parte la ciudad del profeta, el nombre de la ciudad misma, o el nombre de un lugar comprendido en dicha región?', para concluir que existen diferentes opiniones al respecto (Prémare 2002: 100). ¿Hay que pensar que Samhûdî e Ibn Zabâla, o que Ibn Abî Dâwud y Suyûtî trataron a su manera de deconstruir el islam? ¿Cómo explicar los testimonios recogidos por Ibn Sa'd y Tabarî en virtud de los cuales podemos decir que los términos qur'ân y hadith fueron al menos hasta la época de Mu'âwiya más fácilmente intercambiables de lo que comúnmente suponemos? ¿Y qué hacer con las críticas vertidas por Mâlik contra Ibn Ishâq o con las diferencias existentes entre las versiones de la Carta de Medina transmitidas por Ibn Hisham y Abû 'Ubayd?

La objeción de que las verdades de fe podrían verse comprometidas si los datos sobre los que ellas descansan se examinan críticamente no es pues de recibo, ya que se trata de hacer justicia a la complejidad y la diversidad de los datos de que disponemos; y, eventualmente, a sus posibles lagunas y contradicciones. Conviene además no confundir las cosas. El hecho de que el cristianismo naciera en un determinado medio religioso que hoy conocemos mejor y cuyas creencias el propio Jesús reelaboró y legó a una serie de discípulos que, en todo caso, no las recibieron ni interpretaron de forma unívoca, en nada compromete la creencia (cristiana) en la filiación divina y la mesianidad de Jesús, incluso si no podemos llegar a saber con exactitud cómo transcurrió su vida, qué palabras realmente pronunció él y cuáles le fueron atribuidas más tarde, dado que la ciencia histórica no puede, por definición, pronunciarse acerca de lo que es únicamente objeto de fe. Análogamente, el hecho de que la historia de la religión de Israel fuera reescrita y re-creada durante el exilio y el periodo que siguió a éste en función de unas nociones teológicas bien determinadas y contextuables que no fueron empero compartidas por todos, lo que dio pie a las muy diversas tendencias en las que se dividió el judaísmo de la época, de las cuales sólo una logró subsistir tras la destrucción del templo en el año 70 d.C., en nada afecta a la creencia (judía y por extensión cristiana) en un Dios de cuya palabra se hicieron eco los profetas de Israel y de cuyos designios la historia del pueblo judío es la expresión más fehaciente.

Los fieles musulmanes no deberían tampoco inquietarse ante la posibilidad de analizar críticamente las fuentes de la religión que profesan percibiendo en ella un riesgo que no calificarían de tal en el caso de otras confesiones religiosas (véase el artículo de J. J. Tamayo sobre el libro de J. A. Pagola reproducido en http://www.webislam.com/?idt=11422 con fecha 09.11.2008). Al fin y al cabo, 
que, a mediados del siglo VII d.C., un hombre cuyo nombre es mencionado por vez primera en las monedas acuñadas por el califa 'Abd al-Malik en 692 (el testimonio escrito más antiguo con el nombre de Muhammad es un papiro de principios del siglo VIII hallado en Khirbet el-Mird en 1963) creyera ser llamado por el Dios de Abraham e Ismael o fuera efectivamente llamado por él, concedámoslo, para desempeñar una misión profética similar, aunque no idéntica, a la de Jesús y los antiguos profetas de Israel; que ese hombre recibiera una serie de revelaciones que comunicó a los suyos; que éstos las pusieran por escrito tiempo después, cada uno del modo en que creyó haberlas oído o de acuerdo con lo que ciertos testigos les aseguraron haber escuchado; y que, en definitiva, lo así revelado haya terminado por formar parte, aunque probablemente no a título exclusivo, de lo que hoy conocemos por la vulgata uthmaní del Corán (que no sin más por el Corán, cuyas referencias a sí mismo en tanto que palabra revelada, convendría no olvidarlo, son, por lo demás, puntuales y fragmentarias), nada de esto es algo sobre lo que la ciencia histórica pueda pronunciarse, ya que pertenece de suyo al ámbito de las verdades de fe.

La profesión de fe islámica (consistente en la creencia en el Dios Único de Abraham y en la misión profética de Mahoma) no se ve afectada en este punto, aun cuando sí la creencia en la letra del Corán en tanto que palabra increada, pero sobre este particular la propia tradición islámica no ha cesado de polemizar a lo largo de los siglos, y la cuestión permanece abierta. Otra cosa es que los historiadores deban examinar cómo llegó el texto coránico a adquirir su forma definitiva (aunque hay que tener en cuenta también las variantes de lectura que él presenta), lo que evidentemente no pudo suceder de la noche a la mañana sino, como corresponde a la mayor parte de los textos religiosos de la antigüedad (baste citar como ejemplo el libro de Isaías; Blenkinsopp 2000a, 2000b, 2003), a través de un complejo proceso redaccional cuyos diferentes estratos han de investigarse minuciosamente.

Que a la hora de estudiar los orígenes del islam ciertos historiadores contemporáneos muestren sus reservas ante la veracidad de la información contenida en fuentes de carácter más bien literario y didáctico que histórico y ante las cadenas de transmisión oral sobre las que esa información pretende asentarse; que presten cada vez mayor atención al medio religioso judeocristiano en el que el islam surgió, ante el cual las descripciones tradicionales de la Arabia preislámica resultan mucho más problemáticas y mucho menos convincentes; y que hagan uso en sus investigaciones, en resumen, del mismo método que se aplica hoy al estudio de cualquier otro periodo de la historia antigua no debería, en rigor, extrañar a nadie. Hay que atreverse a decir también que cualquiera que sea la actitud desconfiada o abiertamente reprobadora de ciertas jerarquías eclesiásticas frente al estudio histórico-crítico de los orígenes de la religión cristiana, la actitud general de los cristianos hacia dicho estudio es 
más flexible, se mire como se mire, que la actitud de los musulmanes hacia el estudio histórico-crítico de los orígenes del islam. La publicación y sucesivas reediciones del libro antes mencionado de É. Nodet y J. Taylor (1998), dominico el uno y marista el otro de la Escuela Bíblica de Jerusalén, hablan por sí solas a este respecto, y habría análogamente que no perder de vista que fue en los medios protestantes alemanes del siglo XIX donde dicho estudio obtuvo sus primeros frutos. Que 'Ch. Luxenberg' haya juzgado necesario recurrir a un pseudónimo para evitar mayores incidentes tras la publicación de una obra en la que, siguiendo los pasos pioneros de Geiger (1833), Nöldeke (1860; 1910), Fraenkel (1880), Vollers (1981), Barth (1916), Goldziher (1920), Horovitz (1926), Speyer (1931), Jeffery (1938) y especialmente los de Mingana (1927) y Lüling (1974), su autor examina los posibles textos litúrgicos cristianos en lengua siríaca que subyacen a numerosos pasajes del Corán (Luxenberg 2007), puede parecer exagerado.

Pero a tenor de la polémica acaecida en Pakistán tras la aparición de una reseña de dicha obra en la edición internacional de la revista Newsweek su cautela no parece del todo infundada. En cuanto al judaísmo, ¿hay que recordar que cualquiera que pueda ser también la displicente actitud de ciertos grupos ultra-ortodoxos ante el uso del método histórico-crítico aplicado al estudio del corpus bíblico, algunos de los mayores especialistas internacionales en dicha área son precisamente judíos? Obviamente, la hipótesis de que los musulmanes defenderían con más celo su religión porque creerían más en ella que los judíos o los cristianos en la suya parece poco seria como para que debamos contemplarla aquí. Habría más bien que pensar que están menos acostumbrados, simplemente, a poner en cuestión la autoridad de las tradiciones que conforman el meta-relato de sus orígenes, ante el cual tal vez únicamente quepa recordar las palabras de J. Wansbrough reproducidas al comienzo de este breve ensayo: 'los hechos revisten valor en la medida en que son significativos, y su significatividad depende del modo o los modos en que han sido interpretados y preservados' (Wansbrough 2006: 32, la traducción es mía). Y, sin embargo, se concederá, supongo, que la capacidad que los musulmanes tienen de emprender el estudio histórico-crítico de los orígenes de su religión no es menor que la que asiste a los fieles judíos y cristianos en su caso; tampoco son menores sus recursos.

Se objetará que yo mismo prescindí del método histórico-crítico en mi Antología temática del Corán, publicada hace dos años (Segovia 2007). Es cierto. Pero también lo son las muchas dificultades que rodearon su edición desde el principio: la nota preliminar en la que explicaba mis razones para adoptar la versión tradicional de los hechos en una obra destinada a familiarizar al lector no sólo con el texto coránico, sino también y ante todo con el modo en que dan en leerlo e interpretarlo los musulmanes, no fue incluida en las 
páginas iniciales del libro; pese a las reiteradas pruebas de imprenta, el sistema de transliteraciones no fue respetado en la primera mitad de la obra, y en general abundan los errores de imprenta en cuanto a la puntuación de numerosas frases... Demasiados errores y omisiones para un volumen de 293 pp. que, por todo ello, ha envejecido más rápidamente que mis otros libros anteriores (Segovia 2005, 2006a, 2006b). Por otra parte, no haría honor a la verdad si dijera que cuando entregué el libro a la imprenta en 2006 mi estudio de los orígenes del islam había avanzado tanto como lo ha hecho en los últimos tres años de la mano del estudio simultáneo de la apocalíptica judía y de su incidencia en el ámbito judeocristiano.

Volviendo sobre el tema que nos ocupa, hay a mi juicio que distinguir tres opciones. La primera consistiría en aceptar acríticamente el relato tradicional de los orígenes del islam pasando por alto la disparidad de los datos sobre los que él se asienta de manera no siempre enteramente firme. Véase que digo relato tradicional y no fuentes antiguas, ya que estas últimas son menos homogéneas de lo que con frecuencia se supone; inversamente y por lo mismo, hay que atribuir a dicho relato un carácter tardío y básicamente divulgativo, por muy afianzado que él esté en la actualidad. La segunda opción consistiría en poner en cuestión buena parte de las premisas de las que dicho relato parte y un número no menor de las conclusiones que de él pueden extraerse, así como en hacer sitio en la investigación sobre los orígenes del islam a toda una serie de datos suministrados por la arqueología, la epigrafía y la historia política y religiosa de los ocho primeros siglos de la era común, no con la intención de mostrar presuntas falsedades en el interior del relato tradicional, sino de reescribir la historia del islam con la seriedad que ella merece. Y la tercera opción consistiría en adoptar esa nueva metodología con objeto de mostrar lo infundado de las pretensiones religiosas del islam y la precariedad de su base histórica.

Es importante distinguir bien esas tres opciones, ya que si únicamente tenemos en mente la primera y la última difícilmente podremos comprender la especificidad de aquellos estudios que, a lo largo de las últimas cuatro décadas, han hecho suya la que he denominado segunda opción. En otras palabras, la alternativa tradicionalismo/deconstruccionismo no da cuenta de la complejidad del problema.

En líneas generales puede decirse que el estudio histórico-crítico de los orígenes del islam, perfilado ya de algún modo por algunos autores europeos de la segunda mitad del siglo XIX y la primera mitad del XX como I. Goldziher y J. Schacht, tiene su punto de partida en la obra de J. Wansbrough. En dos célebres monografías publicadas a mediados de los años 70 (reeditadas respectivamente en 2004 y 2006) Wansbrough aplicó el método histórico-crítico empleado con éxito en el campo de los estudios bíblicos al conjunto de la literatura 
histórica y religiosa de los primeros cuatro siglos del islam. El análisis de los diferentes aspectos teológicos característicos del texto coránico, la historia de su composición y exégesis, el estudio del medio religioso judeocristiano que proporcionó a los primeros musulmanes sus parámetros conceptuales y herramientas interpretativas, y el examen de cómo ello fue dando lugar, paulatinamente, a la escritura de una historia de la salvación consolidada a comienzos del siglo IX van de la mano en su obra, cuya lectura a menudo difícil debido a su alto nivel académico resulta sin embargo estimulante. No en vano los trabajos de Wansbrough, en los que la substitución del positivismo por un paradigma hermenéutico en el terreno de los estudios históricos juega un papel fundamental, fueron los primeros en investigar pormenorizadamente los primeros siglos del islam y las fuentes que nos permiten conocerlos atendiendo a la evolución del monoteísmo bíblico del que el islam se reclama evitando reducir el primero a una serie de tópicos y negándose a ver en el segundo un hecho excepcional carente de conexiones históricas y teológicas. Y hay que decir que muchos de sus argumentos (que prolongan a su modo los de von Harnack 1909, Schlatter 1918 y Schoeps 1964) continúan siendo no sólo válidos, sino también ineludibles para todo investigador interesado en el estudio de los orígenes del islam (Firestone 2003; Rippin 2004; Hawting 2006b).

El mismo año en que Wansbrough publicó el primero de sus trabajos vio la luz un libro de P. Crone y M. Cook (1977) que, basándose sobre todo en el estudio las fuentes no islámicas contemporáneas de la expansión árabomusulmana, trazaba una visión radicalmente innovadora, y en buena medida controvertida, del modo en que dicha expansión tuvo lugar y de los objetivos que ella se impuso. Según ambos autores, la conquista árabe de los territorios bizantinos obedeció a un proyecto auspiciado por ciertos grupos judíos y árabes de carácter sincrético filo-judío que más tarde rompieron con sus socios dando lugar a una nueva religión. Cualquiera que sea la valoración general que pueda hacerse de las conclusiones alcanzadas en dicha obra, cuestionadas entre otros por Wansbrough en razón de la a su juicio excesiva confianza manifestada por sus autores hacia las fuentes no siempre objetivas analizadas por ellos, hay que reconocer a P. Crone y M. Cook el haber llamado la atención de los historiadores sobre tres puntos: la existencia de fuentes antiguas no musulmanas que han de tenerse presentes, de todos modos, al estudiar la expansión árabe, y que hasta ese momento habían sido ignoradas en su práctica totalidad; la influencia ejercida por ciertos grupos marginales de raigambre judeocristiana en la conversión de los árabes al monoteísmo y en la ulterior formación del islam; y la importancia de los territorios situados al norte de la Península Arábiga, entre Siria y el desierto del Néguev, en el desarrollo del islam durante el siglo VII, aun con anterioridad al establecimiento de la corte omeya en Damasco. 
En trabajos posteriores, Crone ha sometido a una incisiva crítica la imagen habitual de la Arabia preislámica y apuntado hacia el norte de la Península Arábiga como el lugar más probable para el comercio tradicionalmente atribuido al Hijâz (2004), habiendo estudiado también con gran detalle la política (1980) y la evolución del concepto de autoridad en los primeros siglos del islam (2003, en colaboración con M. Hinds). Por su parte, Cook se ha ocupado sucesivamente, en el curso de las últimas tres décadas, de la formación de las creencias islámicas (1981), la biografía de Mahoma (1983) y la estructura y composición del texto coránico (2000), siendo sus contribuciones muy notables en los tres ámbitos.

En una línea parecida a la inaugurada por el libro de Crone y Cook hay que situar la obra conjunta de Y. Nevo y J. Koren (2003), quienes han suministrado un admirable repertorio de datos arqueológicos y epigráficos, verdad es que algunos interpretados de manera discutible, que ponen asimismo de relieve, con todo, la importancia del medio religioso sirio-palestino en el nacimiento del islam y el carácter tardío de su constitución como religión autónoma. Su aportación tampoco puede echarse en saco roto, pues algunos de los testimonios epigráficos en que ambos autores basan su trabajo dejan muy poco lugar a dudas acerca de la evolución de lo que no puede todavía considerarse una religión con plena carta de ciudadanía hacia algo distinto, mucho más definido e independiente, entre finales del siglo VII y mediados del VIII. A su vez, y en la estela de los trabajos de Wansbrough, G. R. Hawting ha investigado la formación del islam atendiendo a la crítica dirigida por este último a la idea de idolatría (1999). Hawting, la relevancia de cuyas investigaciones difícilmente podría pasar desapercibida tanto por lo que hace al estudio de los orígenes del islam como en lo que respecta al estudio comparado de las religiones antiguas, también ha estudiado en posteriores trabajos la creación del califato omeya y su historia (2000) y las formas rituales del islam primitivo (2006a). Mientras que S. M. Wasserstrom (1995) ha analizado con algún detalle las estrechas relaciones existentes entre las religiones judía e islámica entre los siglos VIII y X. Es preciso citar por último a dos autores franceses: A.-L. de Prémare y É.M. Gallez. Gallez (2005) ofrece una visión de conjunto no todo lo sistemática que sería deseable, a la vez que una interpretación muy personal no siempre compartible de los resultados obtenidos por los autores mencionados hasta aquí, y propone enmarcar el nacimiento del islam dentro de la historia general del movimiento mesiánico, desde el esenismo en adelante; reconstrucción que tampoco resulta todo lo rigurosa que cabría esperar, pero cuya intuición de fondo no es desatinada y merecería ser reconsiderada a la luz de nuevos datos. Más modestos pero no menos interesantes son los excelentes trabajos de de Prémare dedicados al examen crítico de las fuentes tradicionales islámicas (2002) y al estudio del Corán como documento histórico y literario (2004). 
El estudio crítico del Corán ha centrado de hecho un buen número de investigaciones originales a lo largo de las cuatro últimas décadas. A los trabajos de Lüling, Wansbrough, Cook, Deroche, de Prémare y Luxenburg antes citados se suman entre otros los de A. Rippin (1983, 2001), M. Cuypers (2002; 2007, en colaboración con G. Gobillot), C. Gilliot (2007), G. S. Reynolds (2007) y M. Kropp (2007). Es obligado mencionar también la obra de H. Berg (2000), deudora en parte de las de Goldziher, Schacht y Wansbrough, sobre la literatura religiosa de los primeros siglos del islam; así como la de R. Meynet, L. Pouzet, N. Farouki y A. Sinno (1998), cuya línea de trabajo Cuypers ha hecho extensiva al estudio del texto coránico, acerca de las formas retóricas características del hadith y las analogías que

ellas presentan respecto de las formas bíblicas, cuestión analizada asimismo por Wansbrough desde una óptica más histórica y hermenéutica que lingüística en sus dos libros. En fin, y junto con los de Lüling, Wansbrough y Luxenberg, los recientes estudios de Sfar (1998), Reeves (2003), Firestone (2003), Bar-Zeev (2005) y Gobillot (2007) han tratado de examinar, en la línea prefigurada por Geiger (1833), Goldziher (1902), Heller (1928), Finkel (193031), Sidersky (1933) y Masson (1958), la presencia de elementos procedentes de la literatura bíblica, parabíblica, neotestamentaria y rabínica en el Corán, campo al que he tratado a mi vez de contribuir con un estudio, parte de otro más amplio actualmente en preparación, sobre el origen de ciertos motivos apocalípticos en el texto coránico (Segovia 2009).

A modo de conclusión el lector encontrará en Berg (2003) una visión panorámica, no exenta con todo de detalles y matices, de los principales métodos y enfoques aplicados durante las últimas décadas al estudio de los orígenes del islam y de la literatura musulmana de los primeros siglos. Sobre los resultados obtenidos en cuanto al estudio del Corán en particular es recomendable la consulta de los trabajos de H. Motzki (2001), G. Böwering (2007) y F. M. Donner (2007), así como las obras ya citadas de Amir Moezzi, Kohlberg, Reynolds y Kropp. Sobre los alcanzados en lo relativo al análisis de la literatura islámica temprana es aconsejable la lectura de Motzki (2003). En su reciente y muy documentada historia general del islam, J. P. Berkey (2003) ofrece, por su parte, una buena síntesis de los principales problemas tratados en las investigaciones de índole histórico-política acerca de la creación del islam y de sus prolegómenos. Mientras que Ibn Warraq (he aquí de nuevo a un autor que ha optado por firmar bajo pseudónimo) ha reunido en dos volúmenes $(1998,2000)$ algunos de los hitos relacionados con el estudio crítico del Corán y de la biografía del profeta del Islam durante los siglos XIX y XX.

En suma, por detrás de las controversias registradas a propósito de tales o cuales teorías, la valoración que cabe hacer de las últimas cuatro décadas por lo que respecta al estudio académico de los orígenes del islam es, a decir verdad, 
muy positiva. No podría ser de otro modo. Si se trata de estudiar seriamente el islam hay que aventurarse a hacerlo de manera a la vez crítica y rigurosa. Los datos históricos merecen ser estudiados, no simplemente creídos o negados. Y los textos merecen ser analizados como lo que son: depósitos de significado pendientes de análisis a expensas del innegable valor que revisten para quienes fundamentan en ellos sus creencias religiosas. La controversia es siempre necesaria y saludable en los foros académicos. Y redunda en la búsqueda y formulación de nuevas perspectivas de estudio. 


\section{Bibliografía}

\section{Siglas}

AB Anchor Bible

BCBO Biblioteca de Ciencias Bíblicas y Orientales

BHFP Biblioteca de Humanidades / Filosofía y Pensamiento

BJRL Bulletin of the John Rylands Library

BSMESB British Society for Middle Eastern Studies Bulletin

CEPSR Colección Estructuras y Procesos Serie Religión

CP Clásicos del Pensamiento

CRINT Compendia rerum iudaicarum ad Novum Testamentum

DRLAR Divinations: Rereading Late Ancient Religions

FCIW The Formation of the Classical Islamic World

HC Histoire et Civilisations

HThS Harvard Theological Studies

JA Journal Asiatique

JSOAS Journal of the School of Oriental and African Studies

MScRel Mélanges de science religieuse

PAAJR Proceedings of the American Academy of Jewish Research

REJ Revue des etudes juives

SBLSS Society of Biblical Literature Symposium Series

SLAEI Studies in Late Antiquity and Early Islam

Amir Moezzi, Mohammad Ali (ed.) 2007 Dictionnaire du Coran (Paris: R. Laffont).

y Etan Kohlberg 2005 'Révélation et falsification: Introduction à l'édition du Kitâb al-qirâ' ât d'al-Sayyârî', JA 293/2: 663-

722.

Barth, Jacob 1916 'Studien zur Kritik und Exegese des Qorāns', Der Islam 6: 113-48.

Bar-Zeev, H. 2005 Une lecture juive du Coran (Paris: Berg International).

Berg, Herbert 2000 The Development of Exegesis in Early Islam: The Authenticity of Muslim Literature from the Formative Period (London: Curzon).

(ed.) 2003 Method and Theory in the Study of Islamic Origins (Leiden: Brill).

Berkey, Jonathan P. 2003 The Formation of Islam: Religion and Society in the

Near East, 600-1800 (Cambridge: Cambridge University Press). 
Blenkinsopp, Joseph 2000a Isaiah 1-39: A New Translation with Introduction and Commentary (AB19; New York: Doubleday).

2000b Isaiah 40-55: A New Translation with Introduction and Commentary (AB19A; New York: Doubleday).

2003 Isaiah 56-66: A New Translation with Introduction and Commentary (AB19B; New York: Doubleday).

Boccaccini, Gabriele 2002 Roots of Rabbinic Judaism: An Intellectual History, from Ezekiel to Daniel (Grand Rapids, MI/Cambridge: Eerdmans).

Böwering, Gerhard 2007 'Recent Research on the Construction of the Qur'ân', en G. S. Reynolds (ed.) The Qur'ân in ItsHistorical Context (London: Routledge): 70-87.

Boyarin, Daniel 2004 Border Lines: The Partition of Judazo-Christianity (DRLAR; Philadelphia: University of Pennsylvania Press).

Brown, Raymond E. 2002 [1997] Introducción al Nuevo Testamento (BCBO 7; 2 vols; Madrid: Trotta).

Charlesworth, James H. 2005 'The Historical Jesus and Christian Origins: Reflections and Methodologies for Future Jesus Research', Henoch 27/12: 35-51.

Cook, Michael 1981 Early Muslim Dogma: A Source-Critical Study (Cambridge: Cambridge University Press).

1983 Muhammad (Oxford: Oxford University Press).

2000 The Koran: A very Short Introduction (Oxford: Oxford University Press).

Crone, Patricia 1980 Slaves on Horses: The Evolution of the Islamic Polity (Cambridge: Cambridge University Press).

2004 [1987] Meccan Trade and the Rise of Islam (Piscataway, NJ: Gorgias Press, $2^{\mathrm{a}}$ ed.).

y Martin Hinds 2003 [1986] God's Caliph: Religious Authority in the First Centuries of Islam (Cambridge: Cambridge University Press, $2^{\mathrm{a}}$ ed.).

y Michael Cook 1977 Hagarism: The Making of the Islamic World (Cambridge: Cambridge University Press).

Cuypers, Michel 2002 'L'analyse rhétorique: une nouvelle méthode d'interprétation du Coran', MScRel 59: 31-57.

y Genèvieve Gobbilot, Le Coran (HC; Paris: Le Cavalier Bleu).

Deroche, François 2007 'Recensiones coraniques', en M. A. Amir-Moezzi (ed.) Dictionnaire du Coran (Paris: R. Laffont): 733-35.

Dix, Gregory 1953 Jew and Greek: A Study in the Primitive Church (London: Dacre Press).

Donner, Fred M. 1998 Narratives of Islamic Origins: The Beginnings of Islamic Historical Writing (SLAEI 14; Princeton: Darwin Press). 
2007 'The Qur'ân in Recent Scholarship: Challenges and Desiderata', en G. S. Reynolds (ed.) The Qur'ân in Its Historical Context (London: Routledge): 29-50.

Dunn, James D. G. 2007 [2005] The New Perspective on Paul: Collected Essays (Grand Rapids, MI/Cambridge: Eerdmans).

Fernández Marcos, Natalio 1998 [1979] Introducción a las versiones griegas de la Biblia (Madrid: CSIC, $2^{\mathrm{a}}$ ed.)

Finkel, Joshua 1930-31 'Old Israelitish Tradition in the Koran', PAAJR 2: 7-21. Firestone, Reuven 2003 'The Qur'ân and the Bible: Modern Studies of Their Relationship', en J. C. Reeves (ed.) Bible and Qur'ân: Essays in Scriptural Intertextuality (SBLSS 24; Atlanta: Society of Biblical Literature): 1-22.

Fraenkel, Siegmund 1880 De vocabulis in antiquis Arabum carminibus et in Corano peregrinis (Leiden: Brill).

Gallez, Édouard-Marie 2005 Le messie et son prophète (2 vols.; Versailles: Éditions de Paris).

Geiger,Abraham 1833 Was hat Mohammed aus dem Judenthume aufgenommen? (Bonn: F. Baaden).

Gilliot, Claude 2007 'Is the Qur'ân Partly the Fruit of a Progressive and Collective Work?', en en G. S. Reynolds (ed.) The Qur'ân in Its Historical Context (London: Routledge): 88-108.

Gobillot, Geneviève 2007 'Apocryphes de l'Ancien et du Nouveau Testament', en M. A. Amir-Moezzi (ed.) Dictionnaire du Coran (Paris: R. Laffont): 57-63.

Goldziher, Ignaz 1889-90 Muhammedanische Studien (2 vols.; Halle: S. M. Niemeyer).

1902 'Isrâ'îliyyât', REJ 46: 63-65.

Harnack, Adolf von 1909 [1885-89] Lehrbuch der Dogmengeschichte (3 vols.;

Tübingen: Mohr Siebeck, $4^{\mathrm{a}}$ ed.).

Hawting, Gerald R. 1999 The Idea of Idolatry and the Emergence of Islam: From Polemic to History (Cambridge: Cambridge University Press). 2000 [1986] The First Dynasty of Islam: The Umayyad Caliphate, AD 661-750 (London: Routledge, $2^{\mathrm{a}}$ ed.).

2006a The Development of Islamic Ritual (FCIW; Aldershot: Ashgate). 2006b 'Foreword' to J. Wansbrough, The Sectarian Milieu: Content and Composition of Islamic Salvation History (New York: Prometheus Books, $2^{\mathrm{a}}$ ed.): i-x.

Heller, Bernhard 1928 'Recits et personnages bibliques dans la légende mahométane', REJ 85: 113-36.

Horovitz, Josef 1926 Koranische Untersuchungen (Berlin: W. de Gruyter).

Ibn Warraq (ed.) 1998 The Origins of the Koran (New York: Prometheus Books). 
(ed.) 2000 The Quest for the Historical Muhammad (New York: Prometheus Books).

Jeffery, Arthur 1938 The Foreign Vocabulary of the Qur'ân (Baroda: Oriental Institute).

Kropp, Manfred (ed.) 2007 Results of Contemporary Research on the Qur'ân: The Question of a Historio-Critical Text of the Qur'ân (Beirut: Orient Institut; Wurzburg: Ergon).

Lüling, Günter 1974 Über den Urkoran. Ansätze zur Rekonstruktion vorislamischer christlicher Strophenlieder im Koran (Erlangen: H. Lüling).

Luxenberg, Christoph 2007 [2000] The Syro-Aramaic Reading of the Koran: A Contribution to the Decoding of the Language of the Koran (Berlin: H. Schiler).

Masson, Denise 1958 Le Coran et la révélation judéo-chrétiene: études comparées (Paris: A. Maisonneuve).

Meynet, Roland, Louis Pouzet, Naïla Farouki, y Ahyaf Sinno 1998 Rhétorique sémitique. Textes de la Bible et de la Tradition musulmane (Paris: Cerf).

Mimouni, Simon Claude 1998 Le judéo-christianisme ancien: Essais historiques (Paris: Cerf).

Mingana, Alphonse 1927 'Syriac Influence on the Style of the Kur'ân', BJRL 11: 77-98.

Motzki, Harald 2001 'The Collection of the Qur'ân: A Reconsideration of Western Views in Light of Recent Methodological Developments', Der Islam 78: 1-34.

2003 'The Question of the Authenticity of Muslim Traditions Reconsidered: A Review Article', en H. Berg (ed.) Method and Theory in the Study of Islamic Origins (Leiden: Brill): 211-58.

Murphy, Frederick J. 1991 The Religious World of Jesus: An Introduction to Second Temple Palestinian Judaism (Nashville: Abingdon).

Nevo, Yehuda, y Judith Koren 2003 Crossroads to Islam: The Origins of the Arab Religion and the Arab State (New York: Prometheus Books).

Newsome, James D. 1979 By the Waters of Babylon: An Introduction to the History and Theology of the Exile (Atlanta: John Knox).

Nickelsburg, George W. E. 2003 Ancient Judaism and Christian Origins: Diversity, Continuity, and Interaction (Minneapolis: Fortress).

2006 [1971] Resurrection, Immortality, and Eternal Life in Intertestamental Judaism and Early Christianity (HThS 56; Cambridge, MASS: Harvard University Press).

Nodet, Étienne, y Justin Taylor 2002 [1998] Essai sur les origins du Christianisme: Une secte éclatée (Paris: Cerf, $2^{\mathrm{a}}$ ed.).

Nöldeke, Theodor 1860 Geschichte des Qorâns (Göttingen: Dieterich). 
1910 Neue Beiträge zur semitischen Sprachwissenschaft (Strassburg: K. J. Trübner).

Prémare, Alfred-Louis de 2002 Les foundations de l'Islam: entre écriture et histoire (Paris: Seuil).

2004 Aux origines du Coran: Questions d'hier, approaches d'aujourd 'hui (Paris: Téraèdre).

Puin, Gerd-Rüdiger 1996 'Observations on Early Qur'ân Manuscripts in San'â”, en S. Wild (ed.) The Qur'ân as Text (Leiden: Brill): 107-11.

Reeves, John C. (ed.) 2003 Bible and Qur'ân: Essays in Scriptural Intertextuality (SBLSS 24; Atlanta: Society of Biblical Literature).

Rendtorff, Rolf 1983 Das Alte Testament: Eine Einführung (Neukirchen: Neukirchener).

Reynolds, Gabriel Said (ed.) 2007 The Qur'ân in Its Historical Context (London: Routledge).

Rippin, Andrew 1983 'The Qur'ân as Literature: Perils, Pitfalls and Prospects', BSMESB 10: 38-47.

(ed.) 2001 The Qur'ân, Style and Contents (Aldershot: Ashgate). 2004 'Foreword' to J. Wansbrough, Quranic Studies: Sources and Methods of Scriptural Interpretation (New York: Prometheus Books, $2^{\mathrm{a}}$ ed.): ix-xix.

Sacchi, Paolo 2004 [1994] Historia del Judaísmo en la época del Segundo Templo (CEPSR; Madrid: Trotta).

Sanders, Edward P. 1977 Paul and Palestinian Judaism: A Comparison of Patterns of Religion (London: SCM; Philadelphia: Fortress).

Schacht, Joseph 1953 [1950] The Origins of Muhammadan Jurisprudence (Oxford: Clarendon, $2^{\mathrm{a}}$ ed.).

Schlatter, Wilhelm 1918 'Die Entwicklung des judischen Christentums zum Islam', EM 64: 251-64.

Schoeps, Hans-Joachim 1964 Das Judenchristentum: Untersuchungen über Gruppenbildungen und Parteikämpfe in der frühen Christenheit (Bern: A. Francke).

Segovia, Carlos A. 2005 Sadr ad-Dîn Shîrâzî: La filosofía islámica y el problema del ser. Estudio y comentario del Kitâb almashâ' ir (BHFP 6; Granada: Editorial Universidad de Granada).

2006a Avicena: Cuestiones divinas (Ilâhiyyât). Textos escogidos (CP 37; Madrid: Biblioteca Nueva).

2006b Al-Ash 'arî: Contra heterodoxos (al-Luma'); o lo que deben creer los musulmanes (CP 38; Madrid: Biblioteca Nueva).

2007 El Corán: Religión, hombre y sociedad. Antología temática (CP 49; Madrid: Biblioteca Nueva). 
2009 'Noah as Eschatological Mediator Transposed: From 2 Enoch 7172 to the Christological Echoes of 1 Enoch 106-107 in the Qur'ân', paper presentado al Fifth Enoch Seminar: International Scholarship on Second Temple Judaism and Christian

Origins, Michigan Center for Early Christian Studies, Istituto Cangiani, Nápoles, 14-18 junio.

Sfar, Mondher 1998 [1997] Le Coran, la Bible et l'Orient ancient (Paris: M. Sfar, $2^{\mathrm{a}}$ ed.).

Sidersky, David 1933 Les Origines des légendes musumanes dans le Coran et dans les vies des prophètes (Paris: P. Geuthner).

Speyer, Heinrich 1961 [1931] Die biblischen Erzählungen im Qoran (Hildesheim: G. Olms).

Trebolle Barrera, Julio 1997 [1993] 'Biblia e interpretación bíblica en Qumrán', en F. García Martínez y J. Terbolle Barrera (eds.) Los hombres de Qumrán: Literatura, estructura social y concepciones religiosas (CEPSR; Madrid: Trotta).

Ulrich, Eugene 1999 'La Biblia copiada e interpretada en Qumrán', en J. Trebolle Barrera (ed.) Paganos, judios y cristianos en los textos de Qumrán (BCBO 5; Madrid: Trotta).

Vander Kam, James C., y William Adler (eds.) 1996 The Jewish Apocalyptic Heritage in Early Christianity (CRINT 3/4; Assen: Van Gorcum; Minneapolis: Fortress).

Vollers, Karl 1981 [1906] Volkssprache und Schriftsprache im alten Arabien (Amsterdam: APA).

Wansbrough, John 2004 [1977] Quranic Studies: Sources and Methods of Scriptural Interpretation (New York: Prometheus Books, $2^{\mathrm{a}}$ ed. con prólogo, traducciones y notas de Andrew Rippin).

2006 [1978] The Sectarian Milieu: Content and Composition of Islamic Salvation History (New York: Prometheus Books, $2^{\text {a }}$ ed. con prólogo, traducciones y notas de Gerald Hawting).

Wasserstrom, Steven M. 1995 Between Muslim and Jew: The Problem of Symbiosis in Early Islam (Princeton: Princeton University Press). 